\title{
Epoxy Composites Based on Resins Having High Flexibility Reinforced with Functionalized Carbon Nanotubes
}

\begin{abstract}
MAGDALENA ADRIANA LADANIUC ${ }^{1 *}$, GHEORGHE HUBCA ${ }^{2}$, RALUCA GABOR ${ }^{1}$, CRISTIAN ANDI NICOLAE ${ }^{1}$, ELVIRA ALEXANDRESCU ${ }^{1}$, TEODOR SANDU ${ }^{1}$

${ }^{1}$ National Research- Development Institute for Chemistry and Petrochemistry (INCDCP-ICECHIM), 202 Splaiul Independentei, 060021, Bucharest, Romania

${ }^{2}$ Politehnica University of Bucharest, Faculty of Applied Chemistry and Materials Science, Bioresources and Polymer Science, 1-7 Gh. Polizu Str., 011061, Bucharest, Romania

The presentpaper was aimed at achieving a study on carbon nanotubes-reinforced composites and involved obtaining and characterization of composites based on epoxy compounds modified with hydroxyl groupscontaining compounds (glycols). In order to obtain high flexibility epoxy resins-based composites, carboxylfunctionalized MWCNTS were used as filler at a concentration of $0.5 \%$. The influence of the weight concentration in CNTs on the mechanical and thermo -mechanical properties of the epoxy compounds was evaluated in comparison to mechanical properties of the DGEBA standard composites reinforced with 0.5 $\%$ MWCNT.
\end{abstract}

Keywords: epoxy composites, functionalized carbon nanotubes; dynamic properties and mechanical properties

Using CNTs as reinforcing agents for epoxy resins might be of particular interest in advanced composite materials. These composites exhibit enhanced mechanical properties, excellent electrical characteristics and elevated thermal conductivity [1-3].

Mechanical properties of epoxy resins are significantly improved by reinforcing small amounts of carbon nanotubes (CNTs). Moreover, using chemically functionalized CNTs with reactive functional groups results in strong interfacial adhesion between polymers/ reinforcing agent, a critical issue in improving the performance of composites. Guadagno et al, [4], Spitalkyi etal. [5] and Theodore et al. [6] demonstrated this matter.

Uniform dispersion of CNTs into epoxy polymer matrices is required for a proper improvement of the mechanical properties of composites. Using various dispersion methods, like mechanical stirring, magnetic stirring, sonication and high shear mixing, provides CNTs dispersion in an epoxy system [7]. Among these methods, sonication is the most commonly employed.

It was reported thataltering the surface of functionalized CNT facilitates good dispersion of the filler in epoxy matrix without agglomeration tendency [8].

Chemical groups such as amino, carboxyl or glycidyl grafted on carbon nanotubes are involved in covalentbonds between the CNTs and epoxy resulting in improved interfacial bonding [9]. The influence of functionalized CNTs and of the temperature at which curing process is conducted on the final interfacial properties of CNTreinforced composites was studied by A. Gadara and collaborators [10].

Elevated mechanical and thermal properties are obtained when using optimal concentrations and CNT functionalization degrees. Literature recommends an optimal degree of filler ranging from 0.5 to $2 \%$ [11-14].

Herein, epoxy composites will be obtained using standard resin/ glycol-modified resin (reinforced with 0,5 $\% M W C N T-C O O H$ ) compounds. The results of the study revealed a good dispersion of CNTs, without agglomeration, is required for mechanical properties improvement; mostly when it comes about flexibility.
The obtained epoxy composites were submitted to mechanical and thermo-mechanical determinations and CNT dispersion in the polymer matrices was analyzed by SEM.

\section{Experimental part}

Materials

Epoxy resin-having high flexibility has been obtained by chemical laboratory modification of the DGEBA resin as explained in [15], with the characteristics given in table 1.

Table 1

CHARACTERISCS OF FLEXIBLE EPOXY RESINS

\begin{tabular}{|c|c|c|}
\hline Glycol & $\mathrm{M}, \mathrm{g} / \mathrm{mol}$ & IoH, $\mathrm{mgKOH} / \mathrm{g}$ \\
\hline EG & 507 & 221.30 \\
\hline DEG & 595 & 188.57 \\
\hline TTEG & 771 & 145.52 \\
\hline
\end{tabular}

Chemıcal moditication was pertormed by synthesis using glycols [ethylene glycol (EG), diethylene glycol (DEG), tetraethylene glycol (TTEG)] and involving LiCl as catalyst at a temperature ranging from 150 to $170^{\circ} \mathrm{C}$ according to the reaction shown in schemel.

It was used a standard resin (RE), DGEBA, provided by Policolor, with an epoxy equivalent of $191.5 \mathrm{~g} / \mathrm{eq}$.

The $\mathrm{COOH}$-functionalized (> 8\%) MWCNTS (Sigma Aldrich, $80 \%$ purity) have an average diameter of $9.5 \mathrm{~nm}$ and length of $1.5 \mu \mathrm{m}$.

Low reactivity crosslinking agent used in the curing reaction (conducted at $100^{\circ} \mathrm{C}$ ) was 4, 4'-methylenedianiline (MDA, supplied by ACROS ORGANICS, $97 \%$ purity) used without further purification.

\section{Obtaining of epoxy composites}

Epoxy resin compounds were obtained using glycolsmodified resin in mixture with standard resin using various ratios between the two components (i.e. 40/60; 50/50 and 60/40).

\footnotetext{
*email: magdaladaniuc@yahoo.com: Phone: 0727774587
} 

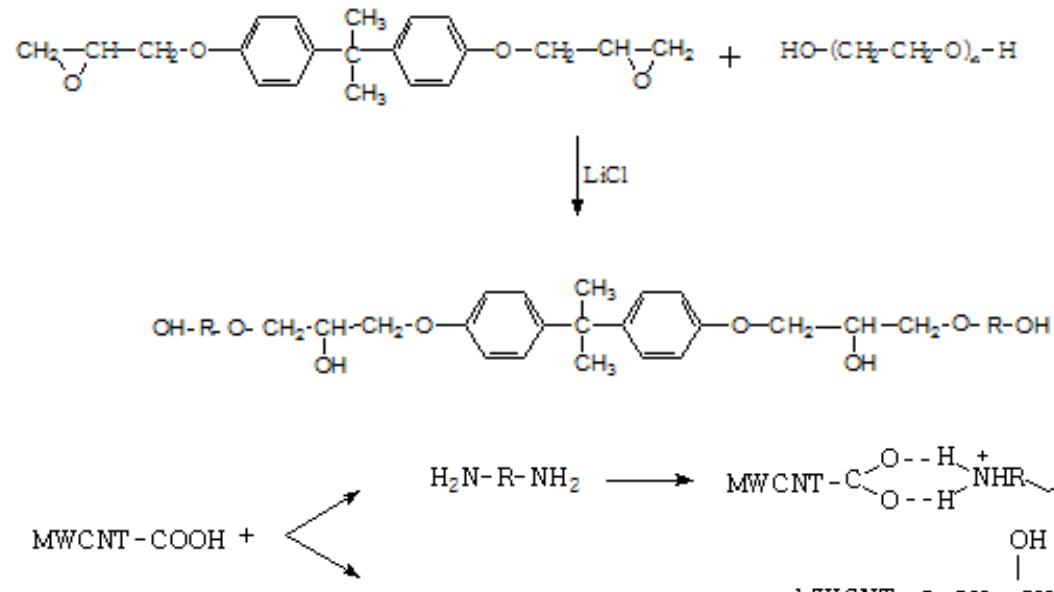

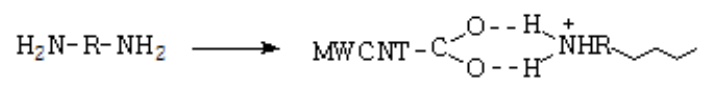

$$
\begin{aligned}
& \mathrm{OH} \\
& \underset{\mathrm{O}}{\mathrm{H}} \mathrm{C}-\mathrm{CH} \longrightarrow \mathrm{MWCNT}-\underset{\|}{\mathrm{C}}-\mathrm{CH}_{2}-\mathrm{CH} \sim
\end{aligned}
$$

Scheme 1. Chemical structure of modified epoxy matrix

Scheme 2. The cross-linking reaction MWCNT-COOH/ epoxy matrix
Mechanical dispersion of MVCNI-CUUH in polymer matrix is carried out by a two-step mixing: (I) it was performed a mechanical dispersion and the mixture was at degassed $110^{\circ} \mathrm{C}$ and then for 30 min under vacuum (20 $\mathrm{mm} \mathrm{Hg}$ for $3 \mathrm{~h}$ ); (II) the resulting mixture was subjected to the mechanical dispersion i.e. homogenization through sonication.

Sonication is achieved on a (ULTRASONICIZER, 750watt, VCX - CV 33) device for $1 \mathrm{~h}$ at $35 \%$ amplitude on pulse mod ( $20 \mathrm{~s}$ on/ $20 \mathrm{~s}$ off) to separate the aggregated CNTs and achieve a good dispersion. During the sonication, (polymer - CNT), viscosity and temperature increase inside the reaction medium, requiring the immersion of the mixture in an ice-water bath.

The nanocomposite suspensions were poured into a Teflon mould and were submitted to the following post curing treatment at $60^{\circ} \mathrm{C}$ for $7 \mathrm{~h}$ and $120^{\circ} \mathrm{C}$ for $7 \mathrm{~h}$. The test specimen pieces ranging in size from $60 \mathrm{~mm}$ (length), 12 $\mathrm{mm}$ (width) and $3 \mathrm{~mm}$ (thickness) were used for the mechanical characterization.

During the crosslinking process, $\mathrm{COOH}$ groups of the carbon nanotube may also react with the amino groups (of the hardener) and with the epoxy resin, as shown in scheme 2.

\section{Sample characterization}

To determine the influence of flexible chains incorporated within the three-dimensional epoxy networks together with the improvement in thermal and mechanical properties of the final compositions as a result of involving CNTs, the obtained samples were submitted to mechanical characterization and DMA tests.

Mechanical tests were carried out according to ASTM standard, using a physical-mechanical testing machine material-Tinus Olsen Machine Class 1; 0-10KN, v=2mm/ $\min$.

DMA tests were conducted on TA Instruments Q800 device operating at an oscillation frequency of $1 \mathrm{~Hz}$, oscillation and amplitude of $20 \mathrm{um}$. The temperature was ramped from 25 to $200^{\circ} \mathrm{C}$ at a heating rate $3^{\circ} \mathrm{C} / \mathrm{min}$.

CNTs dispersion stability and degree of nanotubes agglomeration were also assessed by Scanning Electron Microscopy (SEM). SEM images were recorded in the fracture layer on a FEI QUANTA 200 device, the accelerating voltage ranging from 8 to $15 \mathrm{kV}$.

\section{Results and discussions}

It was investigated the influence of the compound flexibility as compared to the addition of standard epoxy resin simultaneously with the influence of MWCNT- $\mathrm{COOH}$ dispersion in polymer matrices. Variation of physical- mechanical properties of epoxy composites reinforced with $0.5 \% \mathrm{MW}$ CNT-COOH according to these parameters is shown in figures 1-3.

The experimental results presented from figures 1-3, suggest that density of composites is independent on the composition of compound and has values very close to that of standard density resin reinforced with the same percentage of carbon nanotubes. The mechanical properties such as tensile strengths, flexural strength and hardness decrease with increasing the content of modified resin. The elongation at break and impact strength also

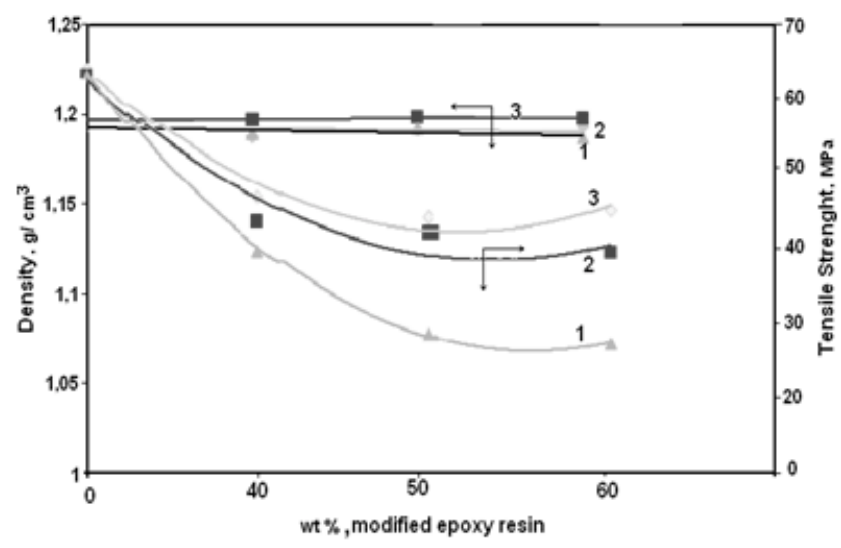

Fig.1 Tensile strength and density dependence vs. the modified resins for: 1. Epoxy composite compound with EG/MWCNT-COOH; 2. Epoxy composite compound with DEG /MWCNT-COOH; 3. Epoxy composite compound with TTEG/ MWCNT-COOH.

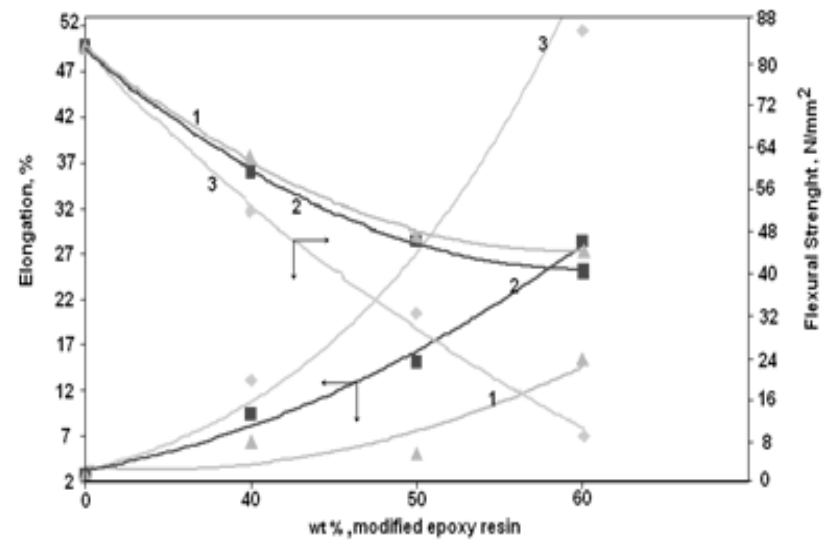

Fig.2 Tensile elongation and flexural strength dependence vs. percentage of modified resins for: 1. Epoxy composite compound with EG/MWCNT-COOH; 2 Epoxy composite compound with DEG /

MWCNT-COOH; 3. Epoxy composite compound with TTEG/ MWCNT-COOH. 


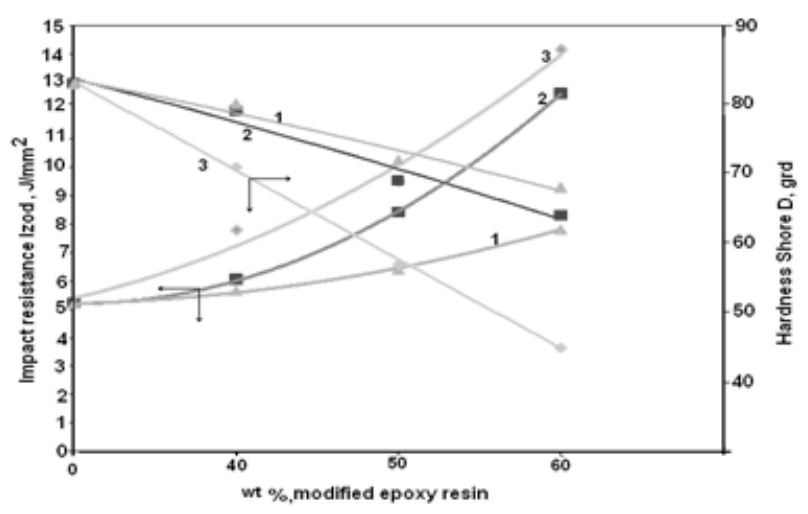

Fig.3. Impact resistance and Shore D hardness dependence vs. percentage of modified epoxy resins for: 1. Epoxy composite with EG /MWCNT-COOH; 2. Epoxy composite with DEG/MWCNT-COOH; 3. Epoxy composites with TTEG /MWCNT-COOH

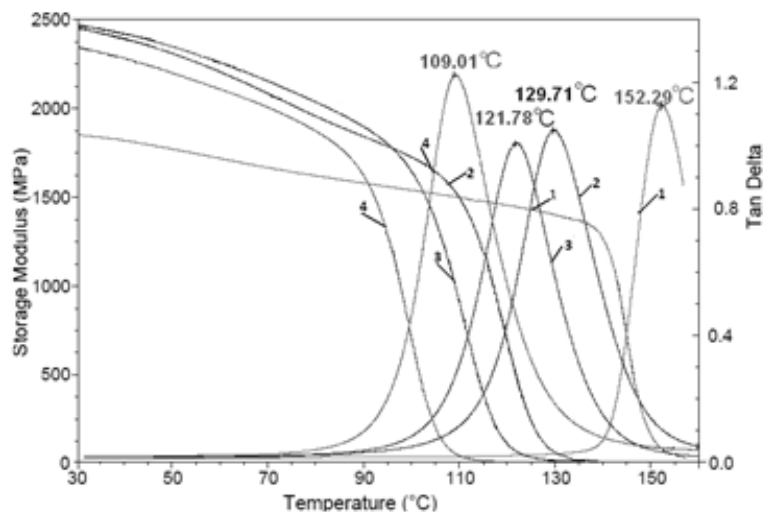

Fig.4. Storage modulus and $\tan \delta$ vs. temperature for:

1. RE composites/MWCNT-COOH 2. Epoxy composite with EG/RE(40/60)/MWCNT-COOH; 3Epoxy composite with EG/RE:(50/50)/ MWCNT-COOH; 4 Epoxy composite with EG/RE:(60/40)/ MWCNT$\mathrm{COOH}$.
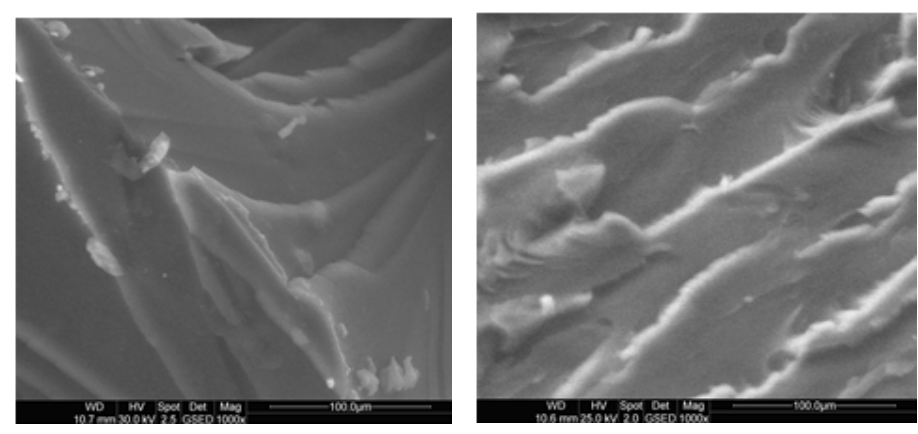

increase when increasing the compound content in modified resin.

Viscoelastic and damping properties of compounds based on modified resin / standard resin reinforced with $0.5 \%$ MWCNT- $\mathrm{COOH}$ are strongly influenced by gravimetric composition of the compound and by the content in carbon nanotubes.

The DMA tests presented in figures 4-6, such as the decrease in storage modulus values, and increasing loss factor, tanä, were in close correlation with glass transition temperatures $(\mathrm{Tg})$.

Carboxyl groups (belonging to CNTs surface) may interact with epoxy resins, resulting in strong CNT-epoxy resin covalent bonds formation and, implicitly in enhanced mechanical properties.

In figure 7a-c, SEM images, recorded in the position of fracture surface are shown for cured epoxy composites reinforced using a weight ratio of $40 / 60$. Uniform surface roughening is observed in (fig.7c) in the position of rupture.

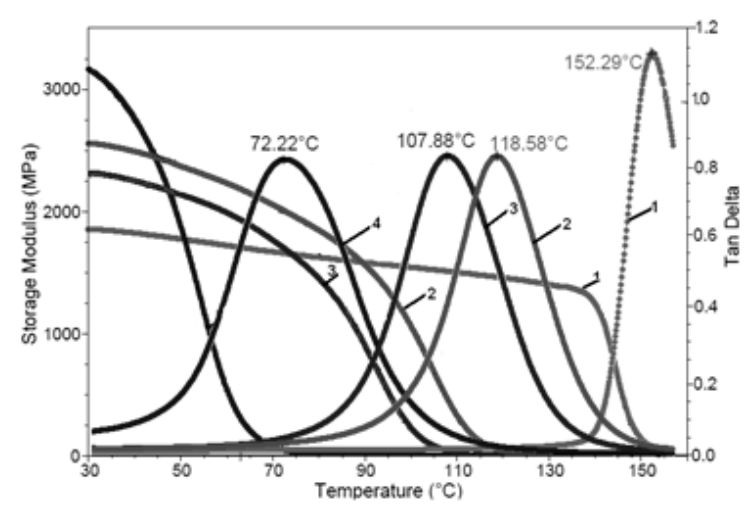

Fig. 5 Storage modulus and $\tan \delta$ vs. temperature for: 1 RE composite /MWCNT-COOH; 2. Epoxy composite with DEG/RE:(60/ 40)/MWCNT-COOH; 3. Epoxy composite with DEG/RE:(50/50)/

MWCNT-COOH ; 4. Epoxy composite with DEG/RE: (60/40) MWCNT-COOH;

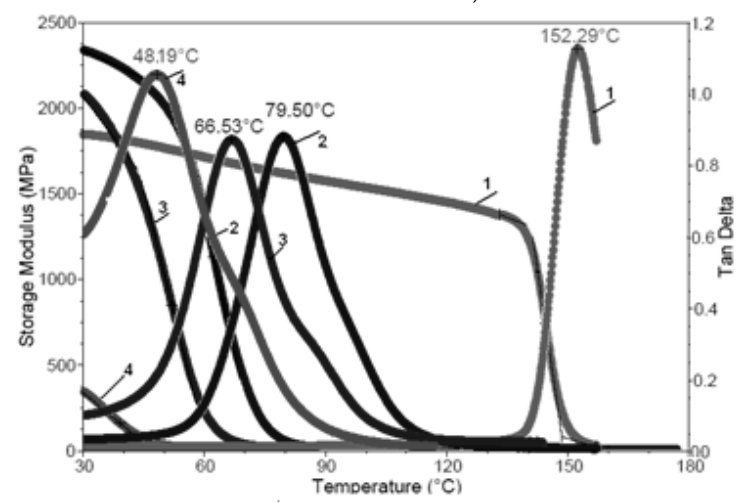

Fig. 6 Storage modulus and $\tan \delta$ dependence vs. temperature for: 1.RE composite /MWCNT-COOH; 2. Epoxy composite with TTEG/ RE: (60/40)/ MWCNT-COOH; 3. Epoxy composite with TTEG/RE: (50/50)/MWCNT-COOH; 4. Epoxy composite with TTEG/RE-(60/40)/ MWCNT-COOH/

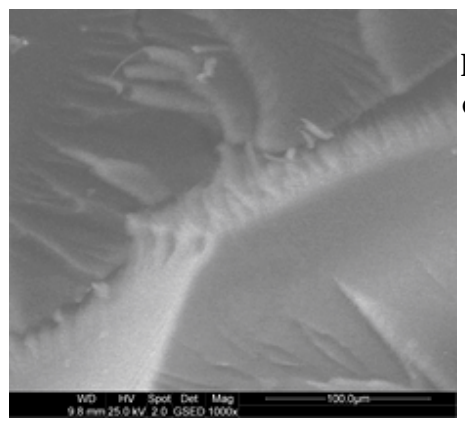

Fig 7(a) SEM images of epoxy composite with TTEG/RE:(40/ 60)/MWCNT-COOH

7 (b) SEM images of epoxy composite with DEG/RE: (40/60)/MWCNT-COOH

7 (c) SEM images of epoxy composite with EG/RE: (40/60)/MWCNT-COOH

Clumps of CNT shown in (fig.b) and less contoured surface roughening in (fig a) may also be noticed.

\section{Conclusions}

Study on the mechanical and thermal properties of composites obtained using standard epoxy resin/glycolsmodified (at 1/2 molar ratio) epoxy resin compounds (reinforced with $0.5 \% \mathrm{MW}$ CNTs-COOH), revealed that the features of the obtained composites depend on the process conditions under which they are fabricated.

Mechanical properties (flexural tensile strength, tensile Shore hardness, elongation at break and impact strength) depend on the molar ratio of involved components in compound obtaining and on the content in carbon nanotubes. The flexibility epoxy compounds increases with increasing content in hardened resin modified. The proper mechanical properties are evidenced for epoxy composites with modified resins/ standard resin weight ratio of (40/ $60)$. 
The glass transition temperature $\left(T_{0}\right)$ determined from DMA highlights once again that compounds flexibility increases the when increasing the concentration in resin.

Good dispersion of functionalized nanotubes, was revealed to the epoxy composite with ethylene glycol and $\mathrm{RE}$ at (40/60) weight ratio, which shows good flexibility, as proved by DMA and SEM.

Functionalized CNT reinforcement of epoxy compounds provides a wide range of flexibility, which significantly expands the range of uses for nanocomposites used in advanced materials for coatings.

\section{Reference}

1.SHIUH-CHUAN HER and CHUN-YU LAl, Materials, 6, 2013, p 22742284;

2.ASHISH WARRIER , AJ AY GODARA, OLIVIER ROCHEZ, LUCA MEZZO, FREDERIC LUIZI, LARISSA GORBATIKH, STEPAN V. LOMOV, AART WILLEM VANVUURE, IGNAAS VERPOEST, Composites: Part A 41, 2010, p 532-538.

3.Q.J. Zhang, S.B. Liang, X.P. Sui Gand Yang, RSC Adv. 5, 2015, p. 25208-25214.

4.NUSRAT JAHAN, ALFRED-TCHERBI NARTEH, MAHESH HOSUR, MUHAMMAD RAHMAN, SHAIK JEELANI, Journal of Composite Materials, 3, 2013, p.40-47
5M. THEODORE, M. HOSUR, J. THOMAS AND S. JEELANI, Materials Science and Engineering: A, 528, no. 3, 2011, p. 1192-1200.

6.M. B. A. SALAM, M. V. HOSUR, S. ZAINUDDIN, S. JEELANI, J ournal of Composite Materials, 3, 2013, p.1-9.

7.BEHROUZARASH, HAROLD S. PARK, TIMON RABCZUK, Composites Part B, 80, 2015, p. 92-100.

8.CHIA-CHING WU, CHEAN-CHENG SU, CHENG-FU YANG, Synthetic Metals 205, 2015, p. 98-105.

9. K. Guru, S.B. Mishra, K.K. Shukla, Applied Surface Science 349, 2015, p. 59-65.

10.A. GODARA, L. MEZZO, F. LUIZI, A. WARRIER, S.V. LOMOV, A.W. VAN VUURE, Carbon 47, 2009, p. $2914-2923$.

11.CAI J IANG, J IANWEI ZHANG, SHAOFENG LIN, SU JU, DAZHI JIANG, Composites Science and Technology 118, 2015, p. 269-275.

12.N.G. SAHOO, S. RANA, J.W. CHO, L. LI, S.H. CHANA, Prog. Polym. Sci. 35, 2010, p.837-867.

13.K.S. KHARE, R. KHARE, J. Phys. Chem. B 117, 2013, p.7444-7454. 14.K.S. KHARE, F. KHABAZ, R. KHARE, ACS Appl. Mater. Interfaces 6, nr. 9, 2014, p. 6098-6110.

15.LADANIUC, M., DUMITRACHE, L., GABOR, R., NICOLAE, C.A., HUBCA, Gh., Mat. Plast., 52, no.4, 2015, p.433

Manuscript received: 31.10 .2016 